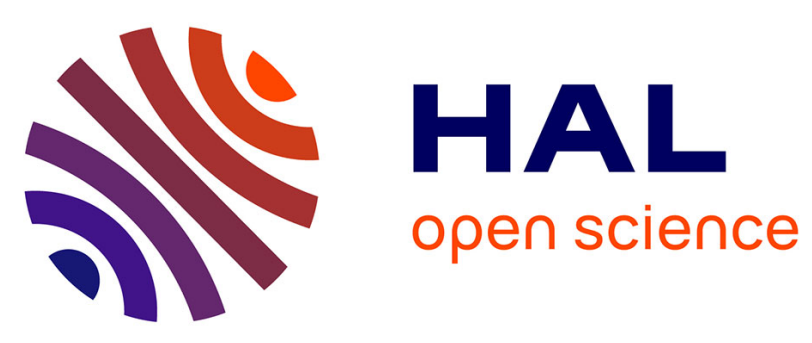

\title{
Flexible and miniaturized microscope for three dimensionnal measurements
}

\author{
Erwan Dupont, Frédéric Lamarque, Tanneguy Redarce
}

\section{To cite this version:}

Erwan Dupont, Frédéric Lamarque, Tanneguy Redarce. Flexible and miniaturized microscope for three dimensionnal measurements. International Symposium on Optomechatronic Technologies (ISOT 2012), Oct 2012, Paris, France. 10.1109/ISOT.2012.6403235 . hal-00800008

\section{HAL Id: hal-00800008 https://hal.science/hal-00800008}

Submitted on 25 Apr 2019

HAL is a multi-disciplinary open access archive for the deposit and dissemination of scientific research documents, whether they are published or not. The documents may come from teaching and research institutions in France or abroad, or from public or private research centers.
L'archive ouverte pluridisciplinaire HAL, est destinée au dépôt et à la diffusion de documents scientifiques de niveau recherche, publiés ou non, émanant des établissements d'enseignement et de recherche français ou étrangers, des laboratoires publics ou privés.

$$
\text { Copyright }
$$




\section{Flexible and miniaturized microscope for three dimensionnal measurements}

\author{
Erwan Dupont, Frédéric Lamarque \\ Université de Technologie de Compiègne \\ Laboratoire Roberval UMR 7337 \\ Compiègne, France
}

\author{
Tanneguy Redarce \\ Institut National des Sciences Appliquées \\ Laboratoire Ampère UMR 5005 \\ Lyon, France
}

\begin{abstract}
In three dimensional measurement systems, two properties are generally difficult to maximize simultaneously: compactness and measurement accuracy. Compactness can be obtained with miniaturized opto-electronic devices such as small cameras. However, quality (resolution, frame-rate, signal to noise ratio...) of these small devices is lower than standard sized ones. In this paper an alternative configuration is described where the opto-electronic devices are not miniaturized but optically connected to small probes through image guides. Instrumental description of this system is detailed and a measurement result is finally presented.
\end{abstract}

Active stereoscopy, compact probe, image guide, digital micromirror device, micro scale

\section{INTRODUCTION}

Three dimensional (3D) measurements in internal structures such as tubular inspection need miniaturized devices. Some usual measurement techniques, like ultrasound ones for example, are difficult to miniaturize. Passive stereoscopy can be a solution with the integration of two small cameras in a small probe [1].

Active stereoscopic measurement strategies have also proved to be adaptable to miniaturized systems. Some methods use projection of patterns generated by the diffraction of light onto precise fabricated grating [2]. Projection of interferograms created by muti-core fibre-based instruments is also a viable strategy [3]. Fringe projection techniques are possible as in [4] where a special helical projector illuminates the inner surface of a cylinder. More flexible pattern projection techniques use a DMD (Digital Micro-mirror Device, Texas Instrument Inc) as projection device for high speed [5] or high accuracy [6] measurements. A DLP (Digital Light Processing, Texas Instrument Inc) based pattern projector and a miniature camera integrated in a compact probe is also described on [7].

The proposed alternative solution is to connect a standard sized camera and a DMD with two compact and flexible optical probes through image guides. The structure of the system is firstly presented, then the properties of the main components and the optical setup are detailed. Finally a measurement result is reported.

\section{SYSTEM OVERVIEW}

To reconstruct the $3 \mathrm{D}$ shape of a sample, the system is built on a two channels active stereoscopic configuration (See fig 1).
The first channel, based on a DMD, is the projection channel while the second channel, based on a digital camera, is the acquisition channel. The incoming light reflected and structured by the DMD is injected into an image guide connected to a compact optical probe. This probe projects the incoming patterns onto the measurement area. A similar design in the acquisition channel allows the capture of images from the measurement area to a digital camera through a second compact probe and another image guide.

Between the projection and acquisition channels, a stereoscopic angle encodes the depth information. The value of this angle was fixed for the experiments at 60 degrees to get a good balance between axial and lateral resolutions. However, the relative positioning of the two probes is flexible and the stereoscopic angle can be changed by moving the probes.

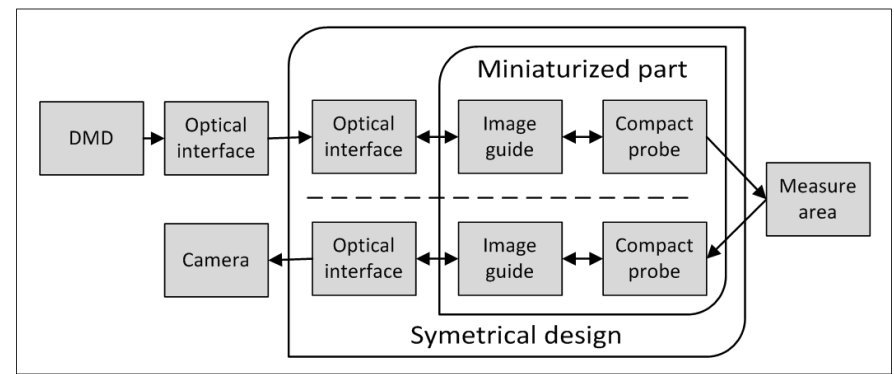

Figure 1. Schematic representation of the 3D measurement system.

\section{IMAGING COMPONENTS}

As stated above, the active element of the projection channel is the DMD. This MEMS device is composed of $1024 \times 768$ squared mirrors of $10.8 \mu \mathrm{m}$ pitch. Each micro-mirror can switch at $32 \mathrm{KHz}$ rate between two discrete positions with only one active position (pixel lighted in the pattern). The DMD allows structuring the incoming light in a flexible way with a large variety of binary patterns. Incoming light source can be of various types. In [8], laser source versus white light source were compared. It was observed that white light sources provided less noisy results, with the drawback of a lower illumination power which lead to decrease the acquisition rate $(1-2 \mathrm{~Hz})$ to enhance the image contrast. By the opposite, the laser illumination, because of the light concentration efficiency onto the DMD, authorized higher frame rate $(15 \mathrm{~Hz})$.

Other main imaging components of the system are the image guides (from Fujikura Inc.). They are optical 
components that copy an image from one of their end to their other end. The number of the optical fibers that compose the image guides we used in the experimental setup is 70000 . Each fiber in the image guide has a diameter of $4 \mu \mathrm{m}$, and the image guide diameter is $1.4 \mathrm{~mm}$, with a length of two meters. In term of image resolution, the image guide is the bottleneck of the system. Indeed, camera and DMD are equivalent of 800 000 pixels imaging devices. Consequently, the resolution of the projection and acquisition channels are limited to 70000 pixels. This lower image resolution will impact the 3D lateral and axial resolutions of the instrument, which have to be evaluated and compared to the values obtained without image guides integration.

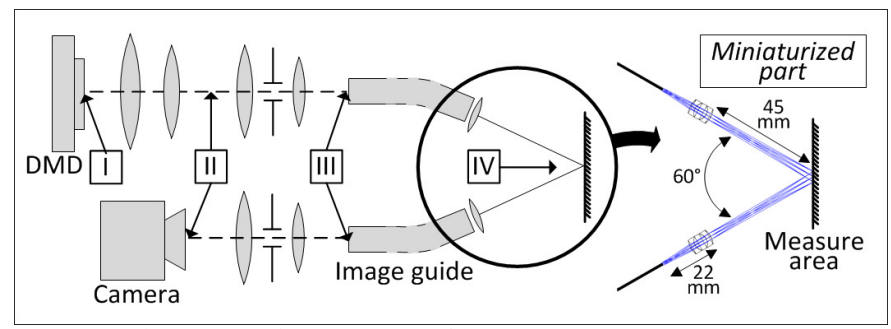

Figure 2. Optical elements of the 3D measurement system

\section{OPTICAL SETUP}

Three optical interfaces (See fig 1) are placed between the DMD, CCD and image guides for image magnification purposes. Due to the image guides cylindrical shape, all transmitted images are circular. Each image size is fixed as follow (See fig 2): at point I, the pattern size fit the DMD matrix and consequently has a diameter of $8.3 \mathrm{~mm}$. At point II, the image size is identical for the two channels due to the symmetrical design of the system and fits the CCD size with a diameter of $3.6 \mathrm{~mm}$. At point III, the images sizes diameters value is of $1.2 \mathrm{~mm}$, which is the picture diameter of the image guides. Finally at point IV, the field of view (FOV) has a size of $5 \mathrm{~mm}$. And considering a working distance of $45 \mathrm{~mm}$, the angle of view is $6.4^{\circ}$. Each optical interface has been optimized with the optical simulation software Zemax (Optima Research Inc.).

The compact probes (22 $\mathrm{mm}$ long) have also been optimized with Zemax. Each probe is composed of a $6 \mathrm{~mm}$ diameter lens and a diaphragm. This lens is a triplet Steinhel which provided in the optical simulation tests with very low geometric and chromatic distortion results. The diaphragm diameter of $1.7 \mathrm{~mm}$ was calculated to give a $2 \mathrm{~mm}$ depth of field (DOF) with limited distortion and diffraction effects.

\section{EXPERIMENTAL RESULTS}

A measurement was done on a 10 cent euro coin (See fig 3). Horizontal lines and a star of $80 \mu \mathrm{m}$ height were measured and well detected. The algorithmic method used for this measurement is detailed in [8]. It is a hybrid phase shift method based on vertical binary lines projection and capture, which leads to the computation of a phase map, a depth map and finally the shape of the measured sample. More experiments, not detailed in this paper, proved that the system has a $3 \mathrm{D}$ axial resolution of $10 \mu \mathrm{m}$ and a lateral resolution of $25 \mu \mathrm{m}$.

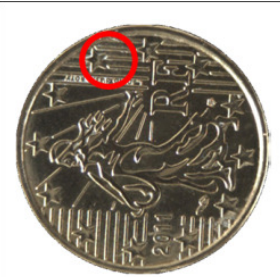

(a)

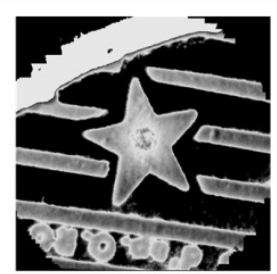

(b)

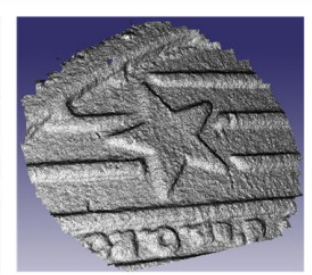

(c)
Figure 3. (a) Measurement area on the 10 cent euro coin. (b) Depth map of the mesured surface. (c) $3 \mathrm{D}$ reconstructed surface

\section{CONCLUSION}

Flexible and miniaturized microscope for three dimensional measurements based on active stereoscopy was described. The two main properties of this system are its miniaturized design and the flexible positioning of both projecting and capture probes. Also, on this system there is a great choice of projected patterns due to the DMD use. A 3D axial resolution of $10 \mu \mathrm{m}$ and a lateral resolution of $25 \mu \mathrm{m}$ were evaluated which leads to the easy detection of the smallest details of a 10 cent euro coin.

Additional measurements on various materials and further improvements are planned such as algorithmic optimization with the test of several 3D reconstruction algorithms, in particular some methods derived from binary gray code. Another improvement could be the variation of the focusing distance of the two compact probes. With this focusing flexibility, the FOV size will also be tunable. Various FOV sizes will be tested and the impact on the 3D resolution studied.

\section{REFERENCES}

[1] Stoyanov, D.; Scarzanella, M.; Pratt, P. \& Yang, G. "Real-time stereo reconstruction in robotically assisted minimally invasive surgery" Medical Image Computing and Computer-Assisted Intervention-MICCAI 2010, Springer, 2010, 275-282

[2] Zhang J., Zhou C., Wang X., "Three-dimensional profilometry using a Dammann grating", Applied optics, Vol 48, Issue 19, pp. 3709-3715, 2009

[3] Yuan L., Yang J., Guan C., Dai Q., Tian F., "Three-core fiber-based shape-sensing application", Optics letters, Vol. 33, (6); pp. 578-580, 2008.

[4] Albertazzi Jr. A. G., Hofmann A. C., Fantin A. V., Santos J. M. C. "Photogrammetric endoscope for measurement of inner cylindrical surfaces using fringe projection", Applied Optics, Vol. 47, Issue 21, pp. 3868-3876, 2008

[5] Huang P., Zhang C., Chiang, F., "High-speed 3-D shape measurement based on digital fringe projection", Optical Engineering, Vol. 42, (1), pp. 163-168, 2003

[6] Tsai M., Hung C., "Development of a high-precision surface metrology system using structured light projection", Measurement, Vol. 38, pp. 236-247, 2005

[7] Fan K.; Li R., Song H., "Fibre image techniques in digital stereomicroscopy", Measurement Science and Technology, Vol. 17, pp. 373-378, 2006

[8] Dupont E, Lamarque F, Prelle C, Redarce T, « Tri-Dimensional optical inspection based on flexible image guide: first step toward 3D industrial endoscopy", Proceedings of the 11th Biennial Conference On Engineering Systems Design And Analysis, ESDA 2012, July 2-4, 2012, Nantes, France 